\title{
Análise das teorias semióticas na ciência da informação brasileira: referentes teóricos
}

Análisis de las teoría semióticas en la ciencia de la información brasileña: referentes teóricos

Analysis of semiotic theories in Brazilian information science: theoretical referents

\author{
Carlos Cândido de ALmeIDA (1), Mona Cleide Quirino da Silva FarIAS (2)
}

(1) Departamento de Ciência da Informação, Faculdade de Filosofia e Ciências, Universidade Estadual Paulista - UNESP, Av. Higyno Muzzi Filho, 737, Marília, São Paulo, Brasil, CEP: 17525-900, Brasil carlosalmeida@marilia.unesp.br

(2) Programa de Pós-Graduação en Ciência da Informação, monaquirino@gmail.com

\begin{abstract}
Resumen
Se identifica y discute la presencia de las teorías semióticas en la literatura brasileña sobre información y documentación. Los resultados muestran que la semiótica de Peirce, a pesar de su reciente aparición en Documentación, ha sido consistente y relativamente dominante en los estudios semióticos del área. Consiguientemente, las teorías semióticas están presentes en la composición teórica de la Documentación en Brasil. Asimismo, los trabajos analizados muestran un cambio de paradigma, desde la perspectiva lingüística hacia la semiótica general.
\end{abstract}

Palabras clave: Teorías semióticas. Documentación. Ciencia de la información. Epistemología. Organización del conocimiento. Peirce, Charles Sanders. Brasil.

\section{Introdução}

Dada as dificuldades polissêmicas, natural do processo de evolução da linguagem humana, a compreensão de outrem, mesmo que este compartilhe de signos linguísticos comuns, nem sempre se realiza. Em determinados contextos sentimos que não basta compartilhar expressões do pensamento, mas contar com uma realidade comum. Segundo Flusser (2007, p. 81-82) "[...] a realidade dos dados brutos é apreendida e compreendida por nós em forma de língua". Em outras palavras, a realidade nos é apresentada pela língua e, segundo o autor, cada língua criaria uma nova realidade. Sem discutir esta tese em termos objetivista ou relativista, identificamos a partir de Flusser um problema ainda maior em se interpretar os signos, mesmo em um contexto científico.

No caso de campos de pesquisa que estudam, organizam e manipulam a linguagem e o conhecimento sistematizado de outras áreas do saber e da ciência, como é o caso da Ciência da Informação (campo que estuda as práticas de informação e os processos envolvidos para isso) as questões da linguagem se agravam. A polissemia e a evolução da interpretação são fenôme-

\begin{abstract}
The presence of semiotic theories in the Brazilian literature on information and documentation is identified and discussed. The results show that Peirce's semiotics, despite its recent appearance on Documentation, has been relatively consistent and dominant in the semiotic studies produced in the discipline. Thus, semiotic theories are present in the theoretical composition of the Brazilian Information Science. Also, the analyzed studies show a paradigm shift from the linguistic perspective towards the general semiotics approach.
\end{abstract}

Keywords: Semiotic theories. Information science. Epistemology. Knowledge organization. Peirce, Charles Sanders. Brazil.

nos reconhecidos pelos pesquisadores e especialistas do campo da Ciência da Informação e talvez as soluções encontradas em uma época, podem não servir a profissionais em outra. Nos ensina Moura (2007, p. 62) que

A estabilidade e a imutabilidade do signo informacional alardeados pelo campo mostrou-se, em termos semióticos, teoricamente falacioso e empiricamente irrealizável.

Os sistemas de organização do conhecimento (1), os sistemas de recuperação da informação, as técnicas adotadas para restringir a busca e a seleção da informação em sistemas automatizados, os métodos de elaboração de esquemas de organização do conhecimento, os métodos de determinação e restrição de significado dos termos, os procedimentos de controle terminológico, o desenvolvimento de sistemas de informação automatizados e, não menos importante, a comunicação da informação em quaisquer ambientes informacionais, supõem todos o tratamento da linguagem e o conhecimento das teorias a ele afeitas, as quais são oriundas da Linguística, Ciências Cognitivas, Filosofia, Sociologia e Semiótica.

Os processos informacionais (2) que envolvem, entre outras coisas, a transferência da informação 
entre as pessoas, são problemas constantes do ponto de vista teórico e prático. Tais processos visam, a grosso modo, levar a informação aos sujeitos da forma mais adequada possível, com o objetivo precípuo de realizar a interação, seja com o recurso às técnicas tradicionais compostas, principalmente, pela interação face-a-face, seja pelo uso massivo de tecnologias de processamento e transmissão de dados.

Tanto a linguagem quanto os processos informacionais são condições indispensáveis da apropriação da informação que requer a codificação e a decodificação de signos, bem como a transmissão destes no espaço e no tempo. A codificação simbólica está presente em todos processos interpretativos, e a linguagem não se estruturaria sem os contratos estabelecidos socialmente. Não há fenômeno informacional que possa ser explicado sem a menção dos códigos e da tradução sígnica. Portanto, seria difícil compreendê-lo sem a referência a fatores semióticos.

Face a isso, o exame dos processos informacionais envoltos nos sistemas de organização do conhecimento e na comunicação da informação dentro do campo da Ciência da Informação leva em conta diversas teorias científicas e abordagens filosóficas. Entre as perspectivas oferecidas para compreender tais fenômenos está o ponto de vista das teorias semióticas (ciência dos signos), em suas mais diversas vertentes. As teorias semióticas contemplam as principais abordagens sobre os signos, a semiose (ação dos signos) e a significação no contexto humano e não humano. Desse modo, teríamos propostas teóricas não antropocêntricas, em que a semiose é estudada de maneira a abarcar o mundo natural, como, segundo Noth (2005, p. 201) o comportamento sígnico de animais na zoossemiótica e dos processos microbiológicos na biossemiótica. Nas aproximações antropocêntricas, o objeto de análise é a semiose no contexto humano e cultural. Entre as diversas teorias semióticas, estão as relacionadas aos teóricos: Charles Peirce (18391914), Ferdinand de Saussure (1857-1913), Louis Hjelmslev (1899-1965), Roman Jakobson (1896-1982), Roland Barthes (1915-1980), Algirdas Julien Greimas (1917-1992), Charles William Morris (1901-1979), Yuri Lotman (1922-1993), Umberto Eco (1932-2016), entre outros comentadores contemporâneos.

Para fins deste artigo, as teorias semióticas foram divididas em duas linhas: teorias peirceanas, as quais recorrem a propositura teórica de Charles S. Peirce (1834-1914), e teorias não peirceanas (linguísticas, culturais e semiológicas), as quais não se vinculam à proposta lógica subjacente aos estudos peirceanos. Reconhecemos que um estudo detido destas configurações teóricas deveria ser empreendido de modo a esclarecer as nuances conceituais e as imbricações existentes, pois estas reúnem um grande complexo de abordagens. Para justificar esta separação mencionamos a influência, no campo semiótico, da obra do filósofo Peirce.

Embora pareça generalizante, e pendendo a uma valorização da teoria semiótica peirceana, essa divisão tem revelado tendências mais globalizantes no trato dos temas. Uma teoria não peirceana, pode valer-se de elementos variados, como do estruturalismo linguístico, do funcionalismo ou da pragmática, sem reconhecer uma continuidade da linha teórica peirceana. Algumas teorias semióticas contemporâneas comportamse assim, o que ficaria difícil classificá-las como estruturalista ou pragmática. Acreditamos que a divisão entre abordagens peirceanas e não peirceanas é mais abrangente além de abrir espaço para as teorias híbridas, as quais se vinculam a mais de uma matriz.

No âmbito da comunidade brasileira de pesquisadores em Ciência da Informação, a análise semiótica dos processos informacionais, com o intuito de recuperar os registros do conhecimento, são os processos que, desde a década de 1960, valem-se de teorias linguísticas para explicar a dinâmica das linguagens e suas condições para uma tradução.

Outros estudos tiveram como foco também a revisão e análise da presença da teoria semiótica na Ciência da Informação, enfatizando os aturores brasileiros, dentro e fora da Ciência da Informação que aportavam elementos à questão. Entre estes, encontramos os trabalhos de Moura (2006), Monteiro (2006), Almeida (2010), Barros e Café (2012) e Vieira (2015).

Este trabalho está relacionado com a pesquisa que investigou a presença das teorias semióticas entre os especialistas em Ciência da Informação no Brasil e teve como objetivo geral a identificação e a análise das teorias semióticas presentes na literatura brasileira de Ciência da Informação. No entanto, o objetivo deste artigo é apresentar, de maneira descritiva, os autores, as fontes de publicação e a filiação teórica de acordo com a abordagem semiótica. Uma futura publicação tratará de versar sobre os trabalhos mais relevantes do ponto de vista semiótico que vem sendo produzidos nos últimos anos.

A pesquisa considerou que a linha semiótica ainda requeria um tratamento amplo, sistematizado e que envolvesse vários elementos do conjunto de processos de informação, da análise à apropriação. No que tange às atividades dos pro- 
cessos de análise de informação, merecia investigar os conceitos semióticos que presidem o tratamento da informação. A hipótese central da referida pesquisa sustentou que as teorias semióticas colaboram à constituição epistemológica da Ciência da Informação no Brasil.

A seguir, serão apresentados os procedimentos metodológicos adotados para compilação do material e na sequência serão descrito os resultados da análise dos autores e fontes principais.

\section{Metodologia}

De acordo com o delineamento adotado, entendemos a pesquisa como bibliográfica. Para a consecução dos objetivos elencados foi necessário recorrer ao tipo conhecido como pesquisa bibliográfica, na medida em que se buscou esclarecer problemas examinando a literatura existente sobre o assunto, identificando e consultando teses, dissertações, livros e artigos relevantes ao tema. Esse conjunto de materiais relevantes também pode ser chamado de corpus. Uma pesquisa bibliográfica levanta a literatura pertinente ao assunto, organizando e sistematizando o material para desenvolver uma discussão. Conforme sustenta Dieterich (1999, p. 178), um objetivo e um problema de pesquisa podem ser alcançados mediante a consulta exclusiva a bibliografia. Desse modo, não consideramos a pesquisa bibliográfica como meramente instrumental para atingir uma pesquisa que requer coleta de dados. A pesquisa bibliografia é um procedimento válido para se confrontar hipóteses, consistindo, então, em um tipo de pesquisa legítima.

A qualidade da pesquisa bibliográfica de, unicamente, verificar, refutar ou retificar uma hipótese, foi a acepção adequada a esta pesquisa. As técnicas aplicadas a pesquisas bibliografias presumem as etapas: identificação das fontes, localização e obtenção do material, leitura do material, compilação e fichamento com crítica sobre a documentação e bibliografia, construção lógica do trabalho e redação do texto.

O universo da pesquisa bibliográfica foi constituído pelos materiais cujos assuntos se correlacionaram aos temas da pesquisa, e divididos em três grupos: a) artigos de periódicos; b) trabalhos em anais de eventos e c) livros/teses/dissertações. A eleição das fontes de pesquisa relacionadas à Ciência da Informação foram orientadas pelos temas/palavras-chave: semiótica, teorias semióticas, teorias semiológicas, epistemologia da Ciência da informação, organização da informação, organização e representação do conhecimento, e outras expressões correlacionadas. 0 levantamento foi realizado entre os anos de 2013 e 2014, e ampliado o prazo de conclusão, recuperando assim documentos no ano de 2015.

Para localizar os artigos de periódicos, primeiramente, selecionamos os principais periódicos da Ciência da Informação, no âmbito nacional recorrendo a base de dados BRAPCl (http://www.bra pci.ufpr.br), além dos periódicos nacionais do campo das teorias semióticas, especificamente Trans/Form/Ação, Cognitio e Cognitio-Estudos, registrando os dados através dos sites. A pertinência dos periódicos justifica-se pela importância acadêmico-científica que possuem em cada uma das comunidades envolvidas, seja entre os pesquisadores em Ciência da Informação e nas teorias semióticas. Em um segundo momento, consultamos os sumários dos volumes e números dos periódicos obtidos e, em seguida, os resumos dos artigos de maior interesse. Com os anais de eventos, adotamos as mesmas estratégias do levantamento realizado com os artigos de periódicos. Esta fonte de informação recolhe trabalhos em sua maioria originais e nem sempre são publicados posteriormente na forma de artigos. Para tanto, consultamos diretamente os sites dos congressos: Portal de eventos da Ancib (http://enancib.ibict.br/index.php/enancib/index/), CINFORM (http://www.cinform2015.ufba.br/) e ISKO Brasil (http://isko-brasil.org.br/). As teses e dissertações referentes às teorias semióticas na Ciência da Informação foram localizadas e obtidas consultando o site dos programas de pósgraduação, os quais oferecem uma lista dos trabalhos defendidos.

$\mathrm{Na}$ sequência, resumiremos os principais resultados relacionados à análise dos autores e suas vinculações teóricas, segundo os propósitos e categorias utilizadas.

\section{Autores e teóricos da semiótica no campo da Ciência da Informação no Brasil}

Esta seção tem por finalidade analisar os autores, as fontes de publicação e a filiação teórica de acordo com a abordagem semiótica. A fundamentação semiótica, que contempla as teorias peirceanas e não peirceanas, pôde ser constatada no contexto da Ciência da Informação brasileira pelos artigos e trabalhos publicados, assim como pela contagem dos autores. Porém, seria uma visão ainda reduzida para conhecer as formas de inserção dos conceitos semióticos, pois há, certamente, um enraizamento histórico das teorias com determinadas escolas. Por exemplo, as abordagens semióticas classificadas como não peirceanas estão mais evidentes, segundo nossa análise, em razão da tradição do pensa- 
mento francês da análise documental de conteúdo na Ciência da Informação no Brasil. A escola de documentação francesa recebeu maior influência da Linguística, como notamos na análise dos trabalhos de Gardin (Almeida, 2011).

A noção de presença é fundamental para conhecer, em um primeiro momento, o surgimento de um assunto na literatura e corresponde à perspectiva da pesquisa qualitativa. A presença de um fenômeno é mais importante que a sua frequência em pesquisas qualitativas. De modo geral, nas pesquisas qualitativas que requerem coleta de dados discursivos, um único depoimento declarado por uma pessoa entrevistada é tratado como fundamental, dada a sua relevância em um contexto, enquanto nem sempre a frequência de um fenômeno ou de uma ideia em um contexto isto é, a taxa de ocorrência (quantidade de vezes que ocorre) -, será mais importante que a qualidade de sua existência (presença).

Em síntese, o que interessou foi saber fundamentalmente quem são os autores e as ideias semióticas por eles professadas, e a quantificação que se segue é apenas um meio para organizar a exposição, pois não foi nosso interesse identificar padrões de citação, apesar de serem arrolados comentários nesse sentido para identificação do núcleo de autores. Cabe acrescentar que, pelo viés quantitativo, notamos pouca representatividade dos trabalhos de Semiótica, como será observado na sequência. Sendo assim, foram recuperados 115 documentos, divididos da seguinte forma: 49 artigos selecionados provenientes revistas da área e de fora da área (representa $42,60 \%$ do total); 41 trabalhos de eventos $(35,65)$ e 25 teses $(21,73)$. Como visto, a maior parte dos trabalhos foi veiculada em artigos científicos, seguida dos anais de congresso.

Nesta análise, destacamos os periódicos, os eventos nacionais e os autores dos trabalhos relacionados à Semiótica. Com esta simples análise, não foi possível aprofundarmos nos temas tratados pelas correntes teóricas. Por um lado, no que tange aos artigos de periódicos nacionais da Ciência da Informação, a lista dos autores mais citados foi produzida partindo dos materiais selecionados. Sendo assim, foram recuperados 23 artigos publicados em 10 periódicos diferentes. Os periódicos com maior destaque foram Encontros Bibli $(21,7 \%)$ e Informação e Sociedade $(17,4 \%)$, como podemos notar a seguir, representando juntos $39,1 \%$ dos artigos, conforme tabela I.

Assim como as iniciativas de Encontros Bibli, outros periódicos têm fomentado nos últimos anos edições específicas sobre novas temáticas no campo da Ciência da Informação, tal como a Se- miótica. Supomos que seja uma forma de contemplar temas antes tratados marginalmente pelas revistas tradicionais. Esse fenômeno potencializa a veiculação de ideias e o aprofundamento de um tema recente na literatura brasileira. Devemos salientar que as revistas foram consultadas desde o primeiro número até o ano de 2014. Considerando este conjunto de trabalhos, pudemos elencar os autores com maior número de publicações, em temas estritamente semióticos, na seguinte ordem: Monteiro, S.D. (5 artigos), Almeida, C.C. (4), Moura, M.A. (3), Lara, M.L.G. (3) e Gomes, H. F. (2).

\begin{tabular}{lcc}
\hline Periódicos & N. & $\%$ \\
\hline $\begin{array}{l}\text { Revista Digital de Biblioteconomia \& Ciência } \\
\text { da Informação }\end{array}$ & 1 & 4,3 \\
\hline Liinc em Revista & 1 & 4,3 \\
\hline Encontros Bibli & 5 & 21,7 \\
\hline TransInformação & 2 & 8,7 \\
\hline Perspectivas em Ciência da Informação & 1 & 4,3 \\
\hline DataGramaZero & 3 & 13 \\
\hline Ciência da Informação & 3 & 13 \\
\hline Informação e Informação & 2 & 8,7 \\
\hline Informação e sociedade: Estudos & 4 & 17,4 \\
\hline Ponto de Acesso & 1 & 4,3 \\
\hline Total & 23 & 99,7 \\
\hline
\end{tabular}

Tabela I. Periódicos Nacionais em Ciência da Informação (Almeida, 2016)

Para a análise de citação referente aos artigos recuperados, seguimos os seguintes procedimentos. Primeiro, a partir dos artigos buscamos todas as referências bibliográficas desses trabalhos e as organizamos em ordem alfabética de autor. Com base nas referências utilizadas pelos trabalhos da lista dos artigos de periódicos nacionais, elaboramos uma tabela na qual arrolamos os autores e o número de vezes que foram citados nos artigos selecionados.

Na sequência, identificamos os autores mais citados e os organizamos por quantidade de citações, considerando todos os textos, dos mais citados aos menos citados. A seguir, apresentamos a tabela II.

\begin{tabular}{lrlr}
\hline Autor & N. & Autor & N. \\
\hline Santaella, L. & 35 & Monteiro, S.D & 5 \\
\hline Peirce, C. S. & 30 & Izquierdo Arroyo, J. M. & 3 \\
\hline Lara, M. L. G. de & 18 & IBRI, I. A & 3 \\
\hline Eco, U. & 14 & Azevedo Netto, C. X. & 3 \\
\hline Almeida, C. C. & 11 & Saussure, F. De & 2 \\
\hline Moura, M.A & 10 & Tellefsen, M.M & 2 \\
\hline
\end{tabular}




\begin{tabular}{llll}
\hline Mai, J.-E. & 8 & Silveira, L.F.B & 2 \\
\hline Pinto, J. & 8 & Blikstein, I. & 2 \\
\hline Nöth, W. & 8 & Merrel, F & 2 \\
\hline Tellefsen, T. L & 5 & Machado, I. & 1 \\
\hline
\end{tabular}

Tabela II. Autores mais citados (Almeida, 2016)

Em terceiro lugar, separamos os autores da Ciência da Informação dos autores vinculados à Semiótica e os organizamos em tabelas distintas, por ordem de citação. O objetivo foi verificar quais os autores com maior número de citações. Nesta fase, os autores citados aparecem conjuntamente, sem a distinção da vinculação teórica e a origem dos autores, se são de Semiótica ou de Ciência da Informação.

Como etapa seguinte, retornamos aos artigos analisados para verificar, com base na lista de referências, quais deles citaram os autores identificados na Tabela II. Além disso, elaboramos as tabelas III e IV com a finalidade de separar os autores pela vinculação disciplinar. Com isso, pretendemos conhecer os autores de Semiótica geral e os autores da Ciência da Informação com maior número de citações.

Com estes dados, foi elaborado uma rede de citação com o auxílio do Software Ucinet (3). A rede de citação representa o universo de autores citados a partir da bibliografia dos autores citantes, consultada e analisada através artigos de periódicos nacionais da Ciência da Informação. Os autores citantes foram representados pelos círculos azuis. Os autores citados foram representados pelos círculos de cor vermelha. Os círculos de cor verde representam os autores que foram citantes e citados ao mesmo tempo. Merece destaque a observação de que quanto maior a espessura da flecha, mais vezes o autor foi citado.

Na página seguinte, apresentamos a rede de autores citados e citantes construída a partir dos autores mencionados anteriormente.

\begin{tabular}{lc}
\hline Autor & N. citações \\
\hline Lara, M. L. G. de & 18 \\
\hline Almeida, C. C & 11 \\
\hline Moura, M. A. & 10 \\
\hline Mai, J.-E. & 8 \\
\hline Tellefsen, T. L. & 5 \\
\hline Monteiro, S. D. & 5 \\
\hline Azevedo Netto, C. & 3 \\
\hline Tellefsen, M. M. & 2 \\
\hline
\end{tabular}

Tabela III. Autores da Ciência da Informação citados (Almeida, 2016)

\begin{tabular}{lc}
\hline Autor & N. Citações \\
\hline Santaella, L. & 35 \\
\hline Peirce, C. S. & 30 \\
\hline Eco, U. & 14 \\
\hline Pinto, J. & 8 \\
\hline Nöth, W. & 8 \\
\hline Izquierdo A, J. M. & 3 \\
\hline Ibri, I. A. & 3 \\
\hline Saussure, F. de & 2 \\
\hline Silveira, L. F. B & 2 \\
\hline Merrel, F. & 2 \\
\hline Machado, I. & 1 \\
\hline
\end{tabular}

Tabela IV. Autores de Semiótica Geral citados

(Almeida, 2016)

Dos autores citados, verificamos duas características: a primeira, a participação efetiva de autores da abordagem peirceana em Semiótica geral (Peirce, Santaella, Pinto, Noth etc.), a segunda, entre os autores da Ciência da Informação citados destacamos os envolvidos com as perspectivas semióticas e linguísticas. Quando observamos a raiz teórica dos autores em Semiótica geral, notamos claramente uma quantidade expressiva de citações no campo da semiótica peirceana em detrimento das abordagens não peirceanas.

Contudo, é com os autores citantes e citados que identificamos um núcleo de especialistas em semiótica atuantes na Ciência da Informação no Brasil. Nesse sentido, figuram os autores Lara, Moura, Monteiro, Azevedo Neto e Almeida. Isso mostra que a comunidade de especialistas em Semiótica na Ciência da Informação no Brasil é relativamente pequena quando comparada aos especialistas atuantes nos núcleos de pesquisa, como organização do conhecimento, gestão do conhecimento ou produção científica. Presumimos que os temas semióticos tenham sido direcionados a aplicações, tal como as questões envolvidas no processo de análise da imagem e análise semiótica de sites.

Há um predomínio de publicações dos autores citados e o maior número de obras foi publicado entre os anos 1990 e 2010. Podemos dizer assim que os anos 1990 foram os que marcaram o surgimento dos estudos semióticos na Ciência da Informação brasileira, primeiramente, tendo seus conceitos traduzidos e compilados através das ideias linguísticas, depois emancipando-se destes e constituindo-se em uma vertente própria revisitando os clássicos da matéria. 


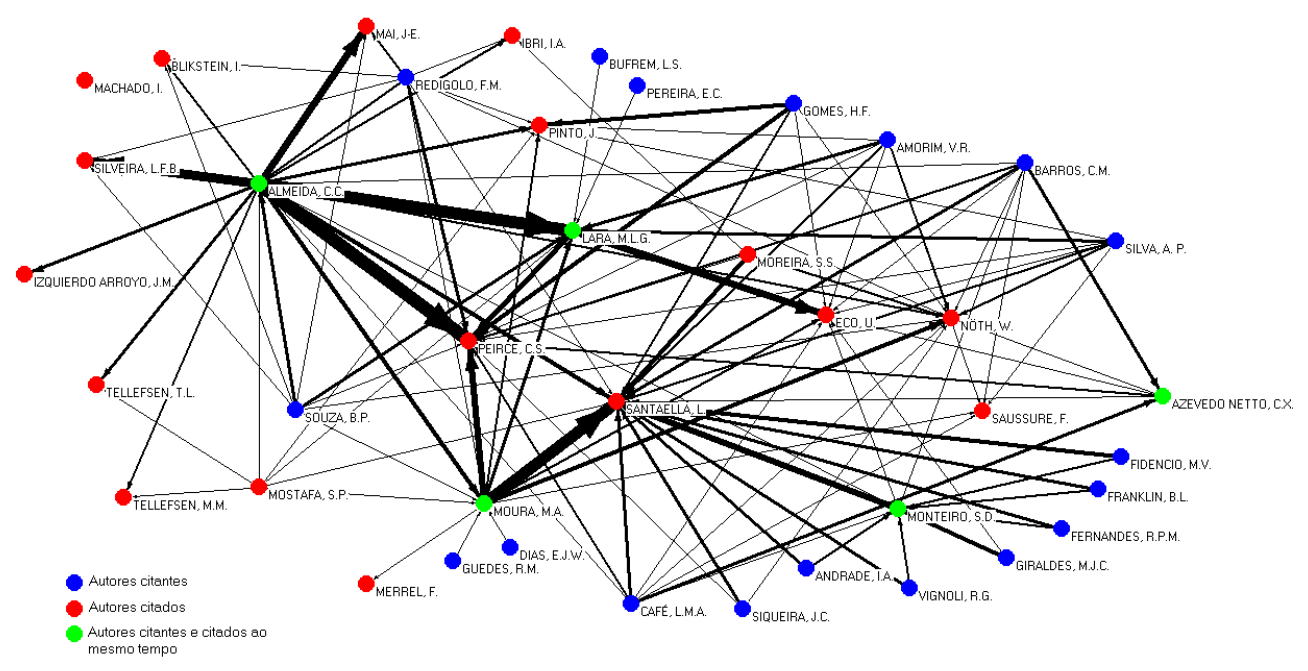

Figura 1. Rede de Autores Citantes e Citados em Periódicos Brasileiros de Ciência da Informação (Almeida, 2016)

Segundo o período destas publicações na Ciência da Informação, presumimos que as obras clássicas da Semiótica, cuja data de publicação é do final da década de 1970 , foram incorporadas de maneira mais significativo a partir de 1990. Contudo, essa é apenas uma das formas de compreendermos o fenômeno da citação de obras publicadas na década de 1970. Uma outra perspectiva, é pensar que os autores brasileiros em Ciência da Informação foram introduzidos a especialistas estrangeiros que versavam a semiótica já na década de 1980. Um caso especial, que demonstrou esse influxo e que contribuiu decisivamente para o processo de integração de temas semióticos e linguísticos na Ciência da Informação no Brasil foi a constituição do grupo Temma, da Universidade de São Paulo. Tal grupo, a partir de um linha francesa, introduziu parte significativa das teorias linguísticas e semiológicas da escola francesa.

Em estudo anterior, Almeida (2014) identificou que entre os temas mais citados: a organização da informação e do conhecimento, a linguagem documental e a análise documental, a Ciência da Informação, a indexação e a análise de assunto. Isto é, foram recuperados 21 artigos publicados em periódicos nacionais na ocasião, tratando da semiótica relacionada aos temas da pesquisa e foi constatado que o tema de maior recorrência na literatura analisada foi a conexão entre semiótica e organização da informação e do conhecimento (Almeida, 2014). A conexão entre semiótica e organização da informação e do conhecimento figurou no estudo de Almeida (2014) em 9 artigos (42,85\%), semiótica e linguagem documental/análise documental em 6 artigos $(28,57 \%)$, semiótica e ciência da informação, com 3 artigos $(14,28 \%)$, semiótica e indexação com 2 artigos (9,52\%), e semiótica e análise de assunto contou com apenas 1 trabalho $(4,76 \%)$. Com a análise dos conceitos trabalhados a seguir será possível materializar as relações apontadas no estudo de Almeida (2014). Sabemos que os estudos de análise documental e organização do conhecimento encontram na Semiótica conceitos de grande interesse para explicar as operações linguísticas e lógicas realizadas sobre os documentos.

Diferentemente do que havíamos pensado em análise anterior (Almeida, 2012), de que a Semiótica em suas várias linhas pudesse desenvolver-se dentro do campo da comunicação e mediação, a Semiótica insere-se na organização do conhecimento, entre outras causas, pela base teórica já construída pelas teorias da linguagem de matriz linguístico-semiológica.

Os resultados do grupo Temma, produzidos na década de 1980 no Brasil pelas obras "Análise documentária: a análise da síntese" e "Análise documentária: considerações teóricas e experimentações" demonstraram cabalmente a estrutura teórica já constituída e consolidada. Esse processo de consolidação alicerçou a introdução de outras teorias semióticas, em especial, a de matriz peirceana. Com isso, concluímos a exposição dos teóricos em Semiótica na Ciência da Informação no Brasil presentes nos artigos.

Por outro lado, os artigos selecionados das revistas em filosofia com incursão no tema semiótica Trans/Form/Ação, Cognitio e Cognitio-Estudos, da primeira edição até o ano de 2014 , totalizaram 26 trabalhos. Contudo, embora os temas em Semiótica possam guardar relação com a Ciência da Informação, não identificamos nenhuma cola- 
boração de autores da área. Dentre os artigos selecionados, $26,92 \%$ (7 artigos) foram de autoria de Silveira, 11,53\% (3 artigos) de Ibri, e 7,69\% (2 artigos) de Santaella. Os demais autores, um total de 17, contaram apenas com um trabalho, sendo que três artigos foram escritos em parceria.

Os anais do Encontro Nacional de Pesquisa em Ciência da Informação (ENANCIB) concentram a maior parte dos trabalhos de semiótica na Ciência da Informação em literatura cinzenta. Dos ENANCIBs, foram analisadas 15 edições (1994, 1995, 1997, 2000, 2003, 2005, 2006, 2007, 2008, 2009, 2010, 2011, 2012, 2013 e 2014), com um total de 2747 trabalhos. Desse total, apenas 21 trabalhos $(0,76 \%)$ mantêm relação com a Semiótica, seja de maneira específica ou indiretamente sob o arranjo temático geral com linguagem, comunicação e mediação.

Esses 21 trabalhos contaram com a participação de 25 autores, mas apenas 4 autores com mais de um trabalho. Os principais autores foram Almeida $(28,56 \%, 6$ trabalhos), Lara $(9,52 \%, 2$ trabalhos), Moura (9,52\%, 2 trabalhos) e Guimarães $(9,52 \%, 2$ trabalhos) e outros autores com apenas um único trabalho cada (Barros, Café, Capolina, Capurro, Coelho, Orrico, Cordeiro, Evangelista, Farias, González Gomez, Gracioso, Assis, Manini, Nakayama, Novellino, Pato, Suescun, Scheiner, Tautain, Weiss, Brascher).

Contudo, restringimos a seleção dos trabalhos que devem tratar de maneira integral de um dos problemas da semiótica e não apenas mencionar conceitos gerais, tal como linguagem. Em razão disso, o número de trabalhos foi reduzido. Observamos que há maior incidência da relação da Semiótica com os temas organização do conhecimento, análise documental de conteúdo, linguística, ciência da informação e epistemologia. Esse dado confirma o encontrado anteriormente sobre os artigos científicos, isto é, a aproximação à semiótica dá-se de maneira teórica e vinculada fundamentalmente à organização do conhecimento. No entanto, necessitamos aprofundar a definição de classes e o lugar teórico-conceitual de cada um destes trabalhos, pois acreditamos que o impacto teórico não é medido unicamente pelo índice de citação, embora seja um indicador válido do potencial de um conceito em um universo.

Os quatro autores citados (Almeida, Lara, Moura e Guimarães) colaboraram com $57,12 \%$ dos trabalhos no campo da Semiótica nos eventos do ENANCIB. Confrontando com os demais autores, podemos inferir que o baixo número de trabalhos geral e a concentração dos trabalhos em poucos autores demonstram que a Semiótica, enquanto objeto de estudo, está em plena fase de desenvolvimento na Ciência da Informação, isto é, a implementação de métodos de análise documental de conteúdo e análise de imagem de base semiótica, bem como a criação de algorítimos para processamento da linguagem que se voltam a Semiótica, são considerados assuntos emergentes. Uma observação adicional é que o número de trabalhos é menor que o número de autores, pois muitos trabalhos foram elaborados em coautoria. Além disso, houve um crescimento dos trabalhos publicados na última década, ainda que isto não represente de maneira alguma uma tendência ascendente.

No Encontro Nacional de Ensino e Pesquisa em Informação (CINFOR), realizado em Salvador, identificamos resultados parecidos com os do ENANCIB, pois apenas quatro trabalhos relacionados à Semiótica, os quais podemos segmentar em dois grupos: um aplicado (um trabalho que aplica as noções semióticas para análise de interfaces digitais) e outro teórico (dois trabalhos que versam sobre problemas da semiótica e um a respeito de sua inserção na formação profissional).

No que tange ainda os anais de eventos, devemos sublinhar outro congresso nacional que mantêm contribuições em Semiótica: os encontros da ISKO-Brasil. Nossa avaliação dos anais ISKO-Brasil 2011, 2013 e 2015 selecionou 17 trabalhos relacionados com a pesquisa. Em 23,52\% (4 trabalhos) dos trabalhos Moraes figura como autor, em 17,64\% (3 trabalhos) aparece Moura, e $11,76 \%$ (2 trabalhos) dos trabalhos são de autoria de Alves, Sabbag ou Fujita. Surgiram também mais 14 autores com apenas um trabalho cada (Almeida, Arboit, Bufrem, Freitas, Assis, Azevedo Netto, Brascher, Candido, Guim, Lima, Medeiros, Ortega, Souza J. e Souza R.). Nesses trabalhos há uma notória presença da semiótica não peirceana - fundamentalmente de matriz greimasiana -, haja vista os estudos de Moraes, Alves e Sabbag, seguidos das contribuições na linha da semiótica peirceana refletidas nos trabalhos de Moura e Almeida.

No caso das monografias, acreditamos ser importante indicar, a título ilustrativo, as produções de teses e dissertações pelos programas de pósgraduação brasileiros no campo da Ciência da Informação. Foi constatado que os trabalhos de pesquisa dessa natureza, assim como as demais publicações, sofreram um crescimento na última década, atestando nossa leitura que sugere uma década da Semiótica nos estudos da informação no Brasil, em comparação a outros períodos. De 1996 a 2005 foram apresentadas 3 teses/dissertações, e nos últimos anos, de 2006 a 2015, foram defendidos 22 trabalhos. Isso se explica, em 
parte, pelo fato de que até 2004 existiam no Brasil apenas quatro programas de doutorado em Ciência da Informação, mas nos anos que se seguiram foram instalados mais cinco cursos em várias regiões do país, totalizando no ano de 2015 nove programas de doutorado. As teses defendidas nestes programas refletiam a diversificação das linhas de pesquisa além da consolidação das já existentes. Assim, as abordagens semióticas puderam ser desenvolvidas em termos qualitativos e quantitativos.

De forma geral, quando comparadas as contribuições dos autores brasileiros com as investigações análogas em outros países, notamos que as bases teóricas peirceana e não peirceana estão presentes também nestes contextos. Em otras palavras, os teóricos citados, especialmente Peirce, Eco e Saussure, são utilizados com o mesmo nível de profundidade em estudos consagrados ao tema nos últimos anos, em especial, nos trabalhos de Izquierdo Arroyo (1990, 1992, 1993, 1995), Izquierdo Alonso (2000, 2004), Izquierdo Alonso e Izquierdo Arroyo (2014), Mai (1997a, 1997b, 2001, 2000 ), Thellefsen $(2002,2003,2004)$, Thellefsen e Thellefsen (2004), Raber e Budd (2003), Friedman e Thellefsen (2011). Em outras palavras, autores representantes das escolas da Ciência da Informação tão diferentes como a espanhola, a americana e a dinamarquesa. A despeito da distância entre as comunidades científicas, o grupo de pesquisadores brasileiros citados demonstra o mesmo nível de profundidade nos estudos semióticos recebido em âmbito internacional.

Seria importante averiguar o conteúdo dessas teses e dissertações, bem como sistematizar os pontos de convergência com as teorias semióticas peirceana e não peirceana. Esse trabalho poderá ser realizado em uma nova pesquisa em que investigaremos os objetos e os métodos das pesquisas semióticos. Contudo, esta análise não foi levada a cabo neste artigo.

No que se refere aos temas, notamos uma preferência pela semiótica peirceana, em detrimento da semiótica greimasiana, semiologia, semiótica da cultura e semiótica da imagem. Embora os dados não visem estimar uma porcentagem entre as abordagens semióticas.

Com base nos levantamentos anteriores, nas tabelas com indicações dos autores mais destacados, construímos um quadro, que ainda merece aperfeiçoamento, pois os autores indicados participam ou utilizam mais de uma abordagem semiótica para dar conta de seus problemas de pesquisa, de tal modo que circunscrever linhas rígidas é um tarefa temerária, mas é um estágio necessário de formalização.

\begin{tabular}{|c|c|c|}
\hline $\begin{array}{c}\text { Teorias e } \\
\text { abordagens }\end{array}$ & $\begin{array}{c}\text { Teóricos em } \\
\text { semiótica geral }\end{array}$ & $\begin{array}{c}\text { Autores } \\
\text { brasileiros em } \\
\text { semiótica }\end{array}$ \\
\hline $\begin{array}{c}\text { Teoria Semiótica } \\
\text { Peirceana/Semió } \\
\text { tica geral }\end{array}$ & $\begin{array}{c}\text { Peirce, } \\
\text { Santaella, Noth, } \\
\text { Ibri, Silveira, } \\
\text { Merrel, Pinto, } \\
\text { Blikstein }\end{array}$ & $\begin{array}{c}\text { Lara, Moura, } \\
\text { Monteiro, Assis, } \\
\text { Amorim, Gomes } \\
\text { Almeida, } \\
\text { Azevedo Netto, } \\
\text { Barros e Café }\end{array}$ \\
\hline $\begin{array}{c}\text { Teorias } \\
\text { Semióticas } \\
\text { Estruturalistas/S } \\
\text { emântica } \\
\text { narrativa/Semióti } \\
\text { ca discursiva }\end{array}$ & $\begin{array}{c}\text { Saussure, } \\
\text { Hjelmslev, Eco, } \\
\text { Greimas, } \\
\text { Barthes, }\end{array}$ & $\begin{array}{l}\text { Lara, Moraes, } \\
\text { Guimarães, } \\
\text { Tálamo, Guarido }\end{array}$ \\
\hline $\begin{array}{c}\text { Teorias } \\
\text { Semióticas } \\
\text { Hibridas/Semióti } \\
\text { ca da } \\
\text { Cultura/Semiolo } \\
\text { gia da imagem }\end{array}$ & $\begin{array}{l}\text { Eco, Lotman, } \\
\text { Machado, } \\
\text { Barthes }\end{array}$ & $\begin{array}{l}\text { Smit, Pato, } \\
\text { Toutain, Silva, } \\
\text { Fujita, Bizello, } \\
\text { Elliott, Mádio, } \\
\text { Farias e Almeida }\end{array}$ \\
\hline
\end{tabular}

Quadro I. Linhas em Semiótica na Ciência

da Informação no Brasil (Almeida, 2016)

O referido quadro ainda requer complementação, pois deveríamos indicar ainda em uma última coluna o conjunto de temas apontados pela literatura que conectam pontualmente a Semiótica com a Ciência da Informação. Desse modo, teremos condições de obter um mapa ou diagrama dos principais assuntos investigados que estabelecem a interface com a Semiótica.

\section{Considerações finais}

Nesta última seção ofereceremos um balanço com as principais conclusões. Considerando os objetivos da pesquisa geral, os quais trataram da análise conceitual e revisão dos trabalhos em periódicos e anais de evento, bem como da identificação dos conceitos semióticos utilizados e principais teóricos, estimamos que estes foram alcançados substancialmente, de modo a facilitar a composição de um diagrama do pensamento da Ciência da Informação brasileira sobre a Semiótica.

Com a classificação adotada das abordagens peirceana e não peirceana foi possível compreender os vínculos teóricos dos autores, bem como os fundamentos utilizados, sinalizando a origem conceitual. Desta forma, respondemos a uma das questões da pesquisa que tratava de apontar a necessidade de saber quais abordagens e teorias semióticas estariam presentes na Ciência da Informação brasileira.

Também aludimos a um núcleo de pesquisadores em Semiótica, relativamente pequeno em comparação à extensão do campo de aplicações e à abrangência de sua teorização. 
No que tange a Semiótica Peirceana, a despeito de seu aparecimento tardio na Ciência da Informação em comparação com as abordagens não peirceanas (linguísticas, culturais e semiológicas), esta mostrou-se coerente e majoritária nos estudos na área. Contudo, a hipótese central da pesquisa, que supôs que as teorias semióticas colaborariam para a constituição epistemológica da Ciência da Informação no Brasil, não pôde ser corroborada, pois a quantidade de trabalhos, apesar da riqueza conceitual, não permite ainda constituir um corpo de conhecimentos consistente e que molde a estruturação conceitual do campo. Isso talvez possa ser alcançado nos próximos anos, quando a tendência na produção em Semiótica identificada mostrar-se constante ou, na melhor das hipóteses, ser ampliada.

Este trabalho também acrescenta elementos à análise realizada por Barros e Café (2012) sobre a interdisciplinaridade dos estudos da semiótica na Ciência da Informação.

Os autores arrolados aqui revelaram indícios de uma mudança de paradigma - pelo menos no âmbito discursivo -, em que há um deslocamento de uma perspectiva linguística para uma Semiótica geral, especialmente na compreensão das ferramentas de organização do conhecimento e dos processos de organização da informação.

\section{Notas}

(1) Segundo Brascher e Café (2008), organização da informação é um processo que envolve a descrição física e de conteúdo de objetos informacionais. Seu objeto de trabalho é formado por registros da informação, mas em seu caráter individual. $\mathrm{O}$ produto da organização da informação é a representação da informação, na forma da descrição física e descrição temática, ambas resultantes dos processos correlacionados: catalogação, classificação, redação de resumos e indexação. A organização do conhecimento, por sua vez, é um processo de construção de modelos de representações de conhecimento. Tem por objeto o mundo das ideias, convertido em conceitos ou aglomerado de conceitos, os quais devem ser analisados para verificação de seus vínculos dispostos em um domínio de conhecimento.

(2) Por processos da informação ou processos informacionais entendemos lato sensu o conjunto de processos resultantes de ações, etapas e fases, que fazem com que especificamente no âmbito da Ciência da Informação - a informação possa ser criada, comunicada e permitir novas apropriações. Desse modo, incluímos os processos de criação (intelectual), produção (registro e edição), seleção, aquisição, tratamento (físico e temático), organização, armazenamento, recuperação, distribuição, mediação, comunicação, utilização e apropriação, realizados nos mais diversos sistemas e ambientes de informação. Cunha e Cavalcanti (2008, p. 293-294) definem processo de informação (information process) como o "processo de comunicação que conduz a um conhecimento mais preciso", mas fazem a seguinte distinção: o processo de comunicação considera os aspectos tecnológicos enquanto no processo informativo a ênfase está na substância das mensagens, ou seja, o conteúdo. A partir disso, também podemos entender como processos da informação os levados a cabo pela cadeia ou ciclo documental, como as operações necessárias para a utilização dos documentos e os pertencentes a cadeia ou ciclo informacional, isto é, "fases pelas quais a informação passa, desde sua criação até sua disseminação."(Cunha, Cavalcanti, 2008, p. 62). A cadeia informacional pressupõe a cadeia documental, pois esta lhe fornece os processos essenciais para a disponibilização da informação. Nesse sentido, os processos elencados por Barreto (2001) nos fluxos interno e fluxos extremos da informação são considerados processos da informação, em outras palavras, processos pelos quais a informação é submetida. As atividades do campo da organização da informação e do conhecimento, bem como as ações que permitem a comunicação da informação em sistemas de informação são consideradas processos informacionais no contexto da Ciência da Informação.

(3) https://sites.google.com/site/ucinetsoftware/downloads.

\section{Agradecimentos}

Agradecemos imensamente o CNPq pelo auxílio recebido e registrado com o processo 406021/2012-0 que permitiu a conclusão desta pesquisa.

\section{Referências}

Almeida, C. C. (2010). Sobre o pensamento de Peirce e a organização da informação. // Anais do XI Encontro Nacional de Pesquisa em Ciência da Informação: Rio de Janeiro, 2010. Rio de Janeiro: PPGCI/UNIRIO, 2010. http://enancib.ibict.br/index.php/enancib/xienancib/paper/view/3412/2538 (2016-07-15)

Almeida, C. C. (2011). Elementos de linguística e semiologia na organização da informação. São Paulo: Cultura Acadêmica, 2011.

Almeida, C. C. (2012). Mediação como processo semiótico: em busca de bases conceituais. // Tendências da Pesquisa Brasileira em Ciência da Informação. 5 (2012) 1-18.

Almeida, C. C. (2014). Indícios da presença de fundamentos semióticos na literatura da ciência da informação. // Scire. 20:1 (ene.-jun. 2014) 65-71.

Almeida, C. C. (2016). A presença das teorias semióticas na ciência da informação brasileira. Marília: s. n., 2016. 128 p. (Relatório de pesquisa relativo ao auxília recebido através do edital MCTI/CNPq/MEC/CAPES No 18/2012).

Barreto, A. A. (2001). A informação em seus momentos de passagem. // DataGramaZero: Revista de Ciência da Informação. 2:4. http://dgz.org. br/ago01/Art_01.htm (200909-27).

Barros, C. M. de; Café, L. M. A. (2012). Estudos da semiótica na ciência da informação: relatos de interdisciplinaridades. // Perspectivas em Ciência da Informação. 17: 3 (jul./set. 2012) 18-33. http://portaldeperiodicos.eci.ufmg. br/index.php/pci/article/view/1501/1050 (2014-04-20).

Brascher, M.; Café, L. (2008). Organização da informação ou organização do conhecimento? // Anais do IX Encontro Nacional de Pesquisa em Ciência da Informação: São Paulo, 2008. São Paulo: ANCIB, 2008. http://www.enancib2008.com.br/ (2008-12-15).

Cunha, I. M. R. F. Coord. (1989). Análise documentária: considerações teóricas e experimentações. São Paulo: FEBAB, 1989.

Cunha, M. B.; Cavalcanti, C. R. O. (2008). Dicionário de biblioteconomia e arquivologia. Brasília: Briquet de Lemos Livros, 2008. 
Dieterich, H. (1989). Novo guia para pesquisa científica. Blumenau: EDFURB, 1999.

Flusser, V. (2007). Língua e realidade. 3. ed. São Paulo: Annablume, 2007.

Friedman, A.; Thellefsen, M. (2011). Concept theory and semiotics in knowledge organization. // Journal of Documentation. 67:4 (2011) 644-674.

Izquierdo Alonso, M.; Sánchez Domínguez, C. (2011). Los estudios de resumen documental en las ciencias de la documentación: un recorrido histórico desde sus orígenes hasta las teorías actuales. // Revista de Lingüística y Lenguas Aplicadas. 6 (2011) 209-227.

Izquierdo Alonso, M. (2000). Nuevos enfoques en el estudio del tratamiento documental de contenido desde los presupuestos de las ciencias del lenguage. // Scire. 6:1 (ene.-jun. 2000) 143-163.

Izquierdo Alonso, M. (2004). Nuevos retos en el análisis documental de contenido: gestión de la forma documental del contenido. // Scire. 10:1 (ene.-jun. 2004) 31-50.

Izquierdo Alonso, M.; Izquierdo Arroyo, J. M. (2014). Entrevista a José María Izquierdo Arroyo, realizada por Mónica Izquierdo Alonso em Alcalá de Henares (Madrid), junio de 2014. // Scire. 20:1 (ene.-jun. 2014) 109-116.

Izquierdo Alonso, M.; Moreno Fernandez, L. M. (2009). El resumen documental: un reto didactico. Madrid: ANABAD, 2009.

Izquierdo Arroyo, J. M. (1990). Esquemas de lingüística documental. Barcelona: Promociones y Publicaciones Universitarias, 1990. Tomos I a III.

Izquierdo Arroyo, J. M. (1990). La ciencia de la búsqueda documental secundaría. // Documentación de las Ciencias de la Información. 13 (1990) 87-111.

Izquierdo Arroyo, J. M. (1992). Cuatro trabajos en curso. // Documentación de las Ciencias de la Información. 15 (1992) 35-65.

Izquierdo Arroyo, J. M. (1993). De la semiótica del discurso a la semiótica documental. // Moreno González, J. A. (eds.). Aplicación de las ciencias del texto al resumen documental. Madrid: Universidad Carlos III, 1993. 199-216.

Izquierdo Arroyo, J. M. (1995). La organización documental del conocimiento. Madrid: Tecnidoc, 1995.

Mai, J-E. (1997a). The concept of subject in a semiotic light. // Schwarts, C.; Rorvig, M. (ed.). Digital collections: implications for users, funders, developers and maintainers. Medford, NJ: Information Today, 1997a. 54-64.

Mai, J-E. (1997b). The concept of subject: on problems in indexing. // Mcllwaine, I. C. (ed.). Knowledge organization for information retrieval: 6th International Study Conference on Classification Research. The Hague: FID, 1997b. 60-67.
Mai, J-E. (2000). The subject indexing process: an investigation of problems in knowledge representation. Austin: Faculty of Graduate School of Library and Information Science, The University of Texas at Austin, 2000. Tesis doctoral.

Mai, J-E. (2001). Semiotics and indexing: an analysis of the subject indexing process. // Journal of Documentation. 57: 5 (Sep. 2001) 591-522.

Monteiro, S. D. (2006). Semiótica peirciana e a questão da informação e do conhecimento. // Encontros Bibli: Revista Eletrônica de Biblioteconomia e Ciência da Informação. 2: número especial $\left(2^{\circ} \mathrm{Sem} .2006\right) 43-57$. http://www.periodicos.ufsc.br/index.php/eb (2006-10-15).

Moura, M. A. (2006). Ciência da informação e semiótica: conexão de saberes. // Encontros Bibli: Revista Eletrônica de Biblioteconomia e Ciência da Informação. 2: número especial $\left(2^{\circ}\right.$ Sem. 2006) 1-17. http://www.periodicos.ufsc.br/index.php/eb (2006-10-15).

Moura, M. A. (2007). Signi-fica ou signi-vai? as teorias da significação no campo da Ciência da Informação. // Reis, A. S. ; Cabral, A. M. (org.). Informação, cultura e sociedade: interlocuções e perspectivas. Belo Horizonte: Novatus, 2007. 61-80.

Nöth, W. (2005). A semiótica no século XX. 3 ed. São Paulo: Annablume, 2005

Raber, D.; Budd, J. M. (2003). Information as sign: semiotics and information science. // Journal of Documentation. 59:5 (2003) 507-522.

Smit, J. W. Coord.(1989). Análise documentária: a análise da síntese. 2. ed. Brasília: IBICT, 1989.

Thellefsen, T. L. ; Thellefsen, M. M. (2004). Pragmatic semiotics and knowledge organization. // Knowledge Organization. 31:3 (2004) 177-187.

Thellefsen, T. L. (2002). Semiotic knowledge organization: theory and method development. // Semiotica. 142:1/4 (2002) $71-90$

Thellefsen, T. L. (2003). Pragmaticism and the role of terminology. Impact: an electronic journal on formalisation in text, media and language, (abr. 2003). http://www.impact.hum.auc.dk (2007-05-05).

Thellefsen, T. L. (2004). Knowledge profiling: the basis for knowledge organization. // Library Trends. 52:3 (winter 2004) 507-514.

Vieira, F. S. (2015). Semiótica peirceana e Ciência da Informação: abordagens na publicação brasileira. Florianópolis: Curso de Biblioteconomia, Universidade Federal de Santa Catarina, 2015. Trabalho de Conclusão de Curso.

Enviado: 2016-04-05. Segunda versión: 2016-07-20. Aceptado: 2016-09-15. 